DOI: $10.7242 / 2658-705 X / 2019.2 .4$

УДК 635.21: 581.143

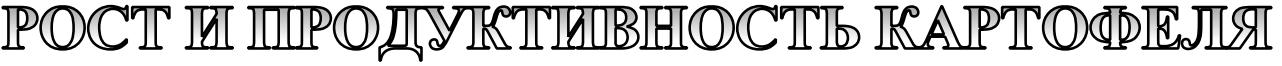

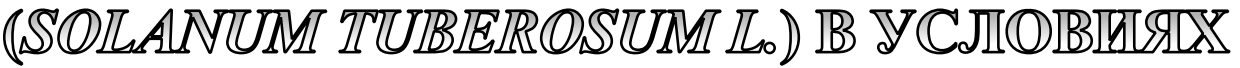 CIBIETOIKY ЛIB TIPIBI
}

А.М. Варушкина, Пермский федеральный исследовательский центр УрО РАН Н.П. Луговская, Пермский федеральный исследовательский иентр УрО РАН А.Ю. Максимов, Институт экологии и генетики микроорганизмов УрО РАН

Картофрель (Solanum tuberosum L.) является одним из ценнейших сельскохозяйственных растений, что обусловливает высокую заинтересованность в изучении оптимальных условий его культивирования. Продуктивность картофреля в условиях северных широт может быть значительно повышена благодаря использованию дополнительных источников света. Данный обзор посвящен проблеме подбора оптимальных параметров досветки картофеля: интенсивности светового потока, продолжительности светопериода, режимов импульсного и непрерывного освещения и спектрального состава.

Рассмотрена роль интенсивности освещения и продолжительности светопериода на рост и развитие проростков картофреля, выявлена проблема подбора оптимального значения данных параметров в связи с сортспецифической реакцией растений. Обсуждается вопрос о целесообразности применения в светокультуре импульсного и комбинированного режимов освещения с точки зрения повышения продуктивности и экономии электроэнергии. Приведены экспериментальные данные разных авторов о влиянии света разного спектрального состава на рост, развитие растений и синтез фоттосинтетических пигментов. Обосновывается выбор освещения с широкими спектральными характеристиками и определенным соотношением интенсивности отдельных спектров. Выявлена возможность использования кратковременного ультрафриолетового облучения проростков картофеля для стимуляции ростовых и биосинтетических процессов, инфракрасного излучения для терморегуляции условий протекания фоотосинтеза и других фризиологических процессов.

Ключевые слова: картофель, Solanum tuberosum L., фотосинтез, светодиодные облучатели, фоторецепторы, LED-светильники, спектральный состав света.

\section{Введение}

Выявить механизмы, согласно которым освещение влияет на рост, продуктивность и жизнеспособность культурного растения - это не самая простая задача.
Электромагнитное излучение Солнца не только служит источником энергии для процесса фотосинтеза, но и является важным регуляторным фактором для процессов морфогенеза, таких как прорастание 
семян, образование корневищ и клубней, формирование генеративных органов, опадение листьев, деэтиоляция и многих других. Фоторецепция обеспечивает тонкую настройку различных биохимических реакций, как, например, фотореактивации - процесса восстановления поврежденных под действием ультрафиолетового излучения молекул ДНК видимым светом (320-500 нм) [6, с. 44; 25, с. 71-75].

Растительные клетки чувствительны к изменению абиотических факторов и внешним воздействиям, таким как влажность, температура, световой режим и даже механическое раздражение [33, с. 701706]. Индуцируемые светом сигнальные пути позволяют растениям достичь оптимального уровня фотосинтеза и свести к минимуму вредное влияние избыточной инсоляции $[1$, с. 12$]$. При смене условий освещения происходит изменение транскрипции благодаря светоиндуцибельным промоторам и светозависимым регуляторным факторам, таким как фитохромы, чувствительные к красному и дальнему красному свету, и криптохромы, осуществляющие рецепцию голубого света и ультрафиолетовых лучей. В дополнение к этому, растения обладают чувствительными к свету механизмами регуляции стабильности иРНК и процесса трансляции $[19$, с. $908 ; 30$, с. $22-27 ; 20$, с. $511-528]$.

Однако свет может оказывать негативное воздействие на растительные клетки. Избыток света, поглощенного фотосинтетическим аппаратом, стимулирует образование вредных для растений активных форм кислорода, таких как супероксидный радикал, гидроксильный радикал, пероксид водорода и синглетный кислород, что приводит к состоянию окислительного стресса. Процесс сопровождается фотоокислением пигментов, деструкцией каротиноидов, обесцвечиванием хлорофиллов и разрушением структур хлоропластов.

Картофель является одним из ценнейших сельскохозяйственных растений, что обусловливает высокую заинтересованность в изучении оптимальных условий его культивирования. Продуктивность картофеля в условиях северных широт может быть значительно повышена благодаря использованию дополнительных источников света. Данный обзор посвящен проблеме подбора оптимальных параметров досветки картофеля: интенсивности светового потока, продолжительности светопериода, режимов импульсного и непрерывного освещения и спектрального состава.

\section{Интенсивность освещения}

Интенсивность освещения напрямую влияет на количество образованных ассимилятов, биомассу растения и на интенсивность поглощения растением углекислого газа. Световая кривая фотосинтеза отражает зависимость его активности от интенсивности оптического излучения в области ФАР (фотосинтетически активной радиации) (рис. 1).

«Отрицательный фотосинтез» (отрезок 1) соответствует ситуации, при которой деструкция ассимилятов при дыхании преобладает над их аккумуляцией при фотосинтезе. С дальнейшим ростом количества квантов света в общем световом потоке интенсивность фотосинтеза линейно возрастает, достигает световой точки компенсации, при которой активность фотосинтеза и дыхания уравновешиваются по газообмену, и достигает положительных значений (отрезок 2). Затем эффективность фотосинтеза падает (отрезок 3) и постепенно выходит на плато «светового насыщения» (отрезок 4), при котором

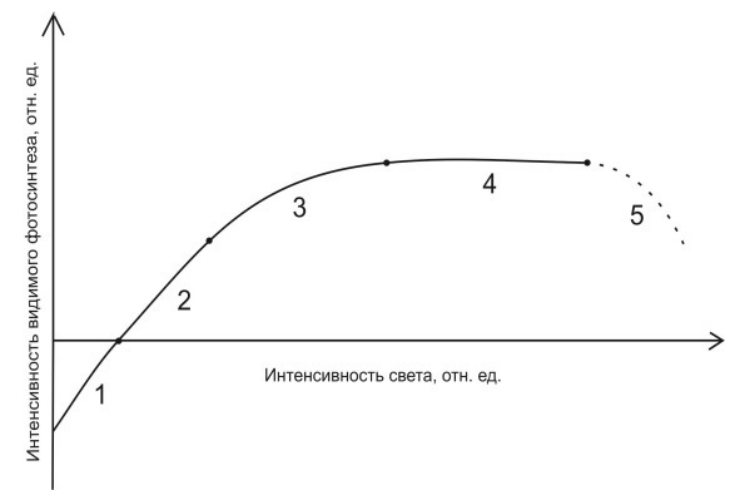

Рис. 1. Типовая световая кривая видимого фотосинтеза 
дальнейшее увеличение плотности светового потока не влияет на интенсивность фотосинтеза. Если продолжить увеличивать интенсивность освещения, это приводит к фотоингибированию, деструкции фотосинтетических структур, что обусловливает падение интенсивности фотосинтеза (отрезок 5) [23, с. 14-18; 17, с. 107-111].

Освещение высокой плотности снижает эффективность фотосинтеза, усиливается транспорт ассимилятов в верхушку побега и, соответственно, ослабляется их транспорт в клубни [28, с. 72-77]. Таким образом, важной задачей при разработке систем искусственного освещения для выращивания картофеля в защищенном грунте является подбор оптимальной интенсивности излучения.

Исследование влияния искусственного освещения на рост и развитие растенийрегенератов картофеля показало, что оптимальная интенсивность облучения при спектре, близком к солнечной радиации, составляет порядка 135 мкмоль квантов на $\mathrm{m}^{2} \cdot$ с. При более высокой интенсивности света (230,1 и 382 мкмоль / м²/c), происходит процесс фотоингибирования, при котором наблюдается подавление процессов роста, формирования листьев и уменьшается биомасса растений [41, с. 35-38]. В исследовании Stutte с соавторами световая точка компенсации для картофеля составила 50 мкмоль $/ \mathrm{m}^{2} \cdot \mathrm{c}$, а световое насыщение достигалось при интенсивности светового потока 1100-1200 мкмоль $/ \mathrm{m}^{2} \cdot \mathrm{c}$ [40, с. 264-268]. В другой работе сообща-

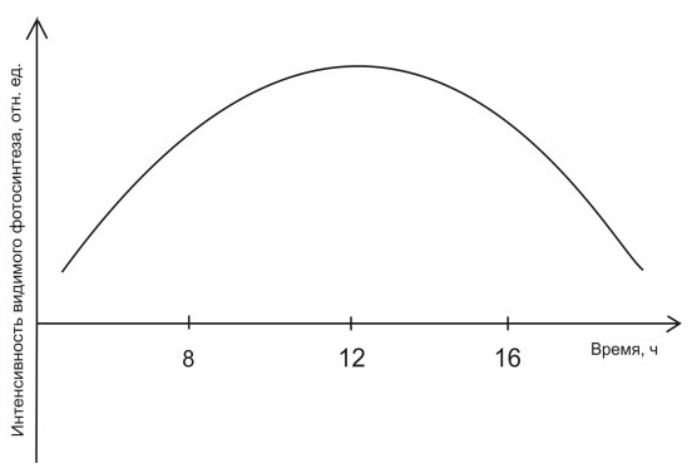

Рис. 2. Суточный ход фотосинтеза при оптимальном значении всех экологических факторов ется, что рост сухой и сырой массы растений, увеличение площади листьев выходит на уровень плато уже при уровне освещенности 90 мкмоль $/ \mathrm{m}^{2} \cdot \mathrm{c}$ [37, с. 15-24]. Вероятно, разница в полученных результатах может быть связана с высотой расположения осветительных приборов, возрастом и сорт-специфической реакцией растений.

В отличие от условий светокультуры в естественных условиях интенсивность солнечного излучения непостоянна и плавно изменяется, увеличиваясь к полудню и снижаясь к вечеру. При оптимальном значении остальных абиотических факторов плотность оптического излучения коррелирует с параболической кривой суточного хода фотосинтеза (рис. 2), однако в природных условиях зачастую наблюдается «полуденная депрессия» фотосинтеза, обусловленная перегревом листа и закрытием устьиц для предотвращения потери влаги (рис. 3) [27, с. 631-632; 21, с. 165-180].

Воспроизведение условий, соответствующих кривой, и комплексное сравнение с условиями постоянной интенсивности позволит ответить на вопрос о целесообразности применения такого режима в условиях светокультуры.

\section{Продолжительность фотопериода}

Продолжительность фотопериода играет большую роль при подборе оптимальных условий культивирования

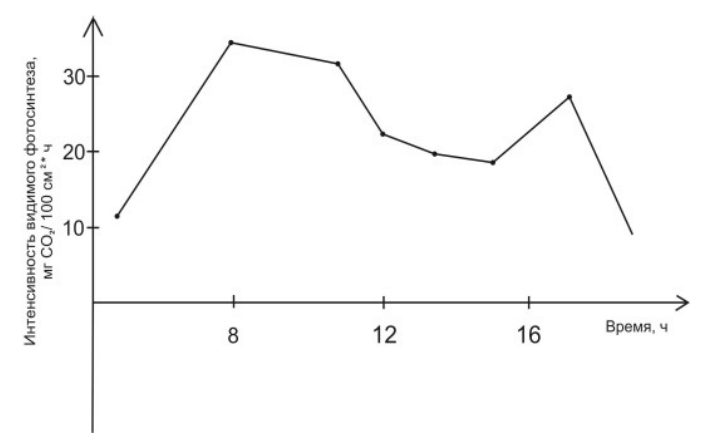

Рис. 3. Дневной ход интенсивности фотосинтеза у картофеля [22, с. 130] 
растений. Многие физиологические и биохимические процессы осуществляются с 24-часовой периодичностью и регулируются при помощи специально предназначенной для этого циркадной системы. Она участвует в регуляции движения листьев, раскрывании и закрывании лепестков венчика, элонгации гипокотилей, открытии устьиц и других физиологических реакциях. На клеточном уровне суточные ритмы определяют интенсивность митоза, фотосинтеза, дыхания и активность некоторых ферментов [26, с. 464].

По цветению и плодообразованию картофель относят к «длиннодневным» растениям, а по клубнеобразованию к «короткодневным». Как правило, после черенкования растения в течение 12 суток облучают, придерживаясь 16-часового режима, и затем, на 30-45-й день, переводят на короткодневный (10-12 ч) фотопериод [2, с. 191].

Увеличение продолжительности фотопериода с использованием искусственного освещения может как повысить, так и снизить продуктивность картофеля. Непрерывное освещение позволяет увеличить сухую биомассу некоторых сортов картофеля более чем в 2 раза по сравнению с 12-часовым световым днем при интенсивности света 200 и 400 мкмоль $/ \mathrm{m}^{2} \cdot$ с $[43$, с. 801-804]. Однако такой интенсивный режим облучения может привести к угнетению роста растений, нарушению формирования и хлорозу листьев у других сортов картофеля и других культурных растений [31, с. 162-166]. Сокращение светового дня до 8-часового периода значительно уменьшает количество образованных ассимилятов, что приводит к угнетению клубнеобразования [35, с. 11588]. Стоит отметить, что продолжительность фотопериода не влияет ни на значение световой точки компенсации, ни на значение интенсивности света, при котором наступает световое насыщение [40, с. 264-268].

\section{Непрерывный, импульсный \\ и комбинированный режимы освещения}

В отличие от остальных источников света LED-лампы могут обеспечивать не только непрерывный, но и импульсный режим освещения, так как они обладают очень малой инерционностью, т.е. способны полностью включаться и выключаться за 200 нс, и, вследствие этого, позволяют формировать очень короткие импульсы [42, с. 261-269], а также разделять во времени импульсы в разных областях спектра. Также стоит отметить, что светодиодные комплексы при схожем спектральном составе оказываются экономичнее люминесцентных ламп, при этом не уступая в стимуляции роста и накоплении биомассы картофелем $[10$, с. $50-56 ; 24$, с. $2-7]$.

Процесс фотосинтеза состоит из световой фазы, где происходит улавливание квантов света молекулами хлорофилла и темновой фазы, на протяжении которой энергия света не принимает участия в химических реакциях. Применение импульсного освещения растений, при котором листовые поверхности облучаются только в световую фазу, позволяет экономить используемую лампами электроэнергию. Хорошо зарекомендовал себя комбинированный режим, при котором период импульсного освещения чередуется с непрерывным. Импульсный период в таком режиме составляет порядка 30 c, продолжительность импульса около 0,5-0,6 c, промежуток между импульсами - 1,0 с. При чередовании 30-секундного импульсного облучения с 15 секундами и более непрерывного облучения уровень стационарного $\mathrm{CO}_{2}$ газообмена у растений не отличается от такового при непрерывном облучении [8, с. 41].

Кроме того, импульсный режим освещения позволяет повысить эффективность фотосинтеза, по сравнению с непрерывным режимом, благодаря снижению диссипации энергии фотонов и ускоренной регенерации молекул хлорофилла. 
Несмотря на преимущества импульсного облучения, на данный момент его применение не обрело достаточной популярности в условиях светокультуры.

\section{Спектральный состав света}

Излучение, способное оказывать регуляторную роль и непосредственно участвующее в процессе фотосинтеза, располагается в диапазоне от 280 до $750 \mathrm{Hм}$ [23, c. $14-18 ; 13$, с. $385-390]$ :

- 280-320 нм - (ультрафиолет В, UVB) - оказывает, как правило, негативное воздействие, повреждая мембранные структуры, молекулы ДНК и фотосинтетических пигментов, однако для нормального развития некоторых видов растений требуется небольшое количество излучения в данном диапазоне;

- 320-400 нм - (ультрафиолет А, UVA) - играет регуляторную роль в развитии растений, поэтому целесообразно присутствие небольшого количества данного диапазона излучения в спектре;

- 400-500 нм - («синий») - имеет субстратное значение и оказывает регуляторное влияние, улавливается фоторецепторными молекулами криптохромов и фототропинов; является обязательной частью излучения при выращивании растений;

- 500-600 нм («зеленый») - не является абсолютно необходимым для обеспечения фотосинтеза, но благодаря своей высокой проникающей способности наиболее эффективен для облучения в загущенном ценозе, растений с оптически плотными листьями;

- 600-700 нм («красный») - обладает ярко выраженным субстратным и регуляторным воздействием, осуществляющимся при участии белков - фитохромов. Красный свет с максимумом излучения 640-670 нм способствует интенсивному росту листьев и осевых органов [18, с. 812-822]. Является обязательной частью спектра для обеспечения фотосинтетических реакций растений.

- 700-750 нм («дальний красный») обладает ярко выраженным регулятор- ным действием. В небольших количествах (несколько процентов) должен входить в состав общего излучения.

В течение дня спектральная плотность солнечной радиации неизбежно меняется: по мере увеличения солнцестояния доля длинноволновой оранжево-красной части спектра сокращается, и когда солнце находится в зените - максимум приходится на коротковолновые сине-фиолетовые лучи, затем происходит обратное уменьшение доли коротковолнового и увеличение доли длинноволнового излучения. Растения обладают физиологическими адаптациями к конкретному режиму спектрального состава света на протяжении светового дня, и его изменения являются сигналами о смене вегетационного периода для растений.

Несмотря на это, нельзя утверждать, что солнечное освещение удовлетворяет всем потребностям выращиваемых растений. Исследование роста картофеля при естественном освещении активно проводилось в 1950-х годах, модуляция освещения осуществлялась посредством затенения ботвы в разное время суток: в полуденное или утреннее/вечернее. Было выявлено, что полуденный свет тормозит процессы роста картофеля, приводит к быстрому отмиранию листьев, в то время как утренний и вечерний стимулирует набор сухой биомассы и клубнеобразование по сравнению с контролем (без затенения). Однако однозначно интерпретировать полученные результаты нельзя, так как полуденный и утренне-вечерний свет различаются как по интенсивности, так и по спектральному составу. Пролить свет на данный вопрос позволила бы имитация изменения спектрального состава солнечного излучения в течение дня при тщательном подборе интенсивности, которая не приводила бы к ингибированию фотосинтеза.

Изучение роста картофеля in vitro [36, с. 380-382] показало нецелесообразность разделения во времени облучения в разных областях спектра. Использование режима, при котором растения освещают- 
ся красным и синим светом поочередно 8часовыми периодами (при 16-часовом световом дне), приводит к снижению темпов роста картофеля. Лучшие результаты обеспечивает полное совмещение данных спектров при облучении растений. Стоит отметить, что при сокращении продолжительности облучения, как в красной, так и в синей области спектра, несмотря на соответствующую компенсацию интенсивности, также будут уменьшаться и масса побега, и масса листьев.

Согласно литературным данным, сокращение спектрального состава света до узкого набора ФАР не всегда дает преимущества при культивировании картофеля. С одной стороны, сокращение спектра позволяет уменьшить затраты на электроэнергию, с другой стороны, это может привести к падению продуктивности.

В условиях низкой интенсивности облучения (60-65 мкмоль / м².c) использование узкоспектрального синего, зеленого и красного излучения приводит к снижению накопления биомассы растениями по сравнению с белым светом соответственно на 49,5, 75,6 и $67,5 \%$ [12, с. 680 687]. При облучении саженцев светодиодами красного спектра (КС) значительно больше сухой биомассы накапливается в аттрагирующих органах - стебле и корнях, по сравнению со светодиодами СС, 3С, БС. Другие исследования демонстрируют стимуляцию узкополосным КС (625 нм) увеличения листовой поверхности [16, с. 189]. Исследователи отмечают сложности в выявлении роли отдельных спектров на процессы корнеобразования, так как влияние узкополосного света не имеет определенной направленности и изменяется в зависимости от сорта.

В свою очередь использование комбинированного режима излучения с длинами волн 660 и 450 нм, может приводить к значительному повышению эффективности фотосинтеза, однако этот потенциал не реализуется в отношении продуктивности в условиях узкоспектрального облучения, что приводит к низкой скорости роста и накопления биомассы растениями картофеля [11, с. 107-112].

Выделенный из хлоропластов и очищенный в лабораторных условиях хлорофилл поглощает свет преимущественно в красной (650-700) и синей (430-460) области спектра [34, с. 133]. Однако пигменты в живой растительной клетке поглощают свет во всем диапазоне от 400 до 700 нм и передают его энергию хлорофиллу [13, с. 36-50]. Сокращение спектральных характеристик используемого света может снизить эффективность множества физиологических процессов, связанных с ассимиляцией азота, фосфора, синтеза пигментов, антиоксидантов и других соединений, что может привести к замедлению роста растений и ухудшению органолептических свойств конечного продукта [39, с. 988]. Таким образом, более целесообразно использовать для освещения растений не узкоспектральные лампы, а лампы белого света, достаточно интенсивные в области ФАР.

Таким образом, приведенные выше наблюдения свидетельствуют о необходимости для нормального развития растения также и других длин волн, кроме тех, необходимость которых обусловлена максимумами поглощения пигментов фотосинтетической системы и рецепторами исследованных сигнальных систем. В том числе тех диапазонов, влияние которых на рост растений и физиологические процессы в настоящее время не исследовано или ранее считалось несущественным.

Многие исследования доказывают эффективность использования досветки растений красным светом. Она позволяет увеличить прирост биомассы картофеля, высоту растений и общую площадь листьев in vitro, ускорить образование адвентивных корней у микроклонов [3, с. $133-144 ; 15$, с. $72-75 ; 4$, с. $62-66]$.

Досветка красным и синим светом увеличивает уровень хлорофилла $a$, хлорофилла $b$ и каротиноидов по сравнению с уровнем пигментов в листьях, фотосинтезирующих под лампами белого света 
[3, с. 133-144; 38, с. 67]. Некоторые исследования демонстрируют наибольшую стимулирующую активность узкополосного желтого света (590 нм) на синтез пигментов [16, с. 189]. Досветка красным или синим узкоспектральным светом в темное время суток позволяет увеличить урожай картофеля in vivo. Стоит отметить, что эффективность такой стимуляции будет сильно варьироваться в зависимости от сорта [29, с. 341]. Узкоспектральный синий свет может увеличивать концентрацию фотосинтетических пигментов у некоторых сортов картофеля и не оказывать видимого влияния на другие сорта [14, с. 46-49]. Активный синтез пигментов играет важную роль в адаптации растений к различным изменениям условий произрастания и свидетельствует о высокой пластичности растений.

Изучение роста картофеля в условиях in vitro выявило стимулирующие свойства синего света (430-480 нм) на ростовые процессы картофеля [5, с. 215-218]. Сухая масса микроклонов картофеля, выросших в режиме досветки на синем свету, достоверно превышала этот показатель в вариантах на красном свету. Стоит отметить, что синий спектр ингибирует растяжение междоузлий и, соответственно, рост растений в длину, что является неблагоприятным фактором для микроклонального размножения.

На данный момент определение оптимального состава спектра искусственного освещения проводилось в отношении только некоторых культурных растений: салата, редиса, подсолнечника, перца, левзеи сафлоровидной, китайской капусты и др. - на основании которых были сделаны выводы о следующем оптимальном соотношении отдельных спектров: $25-30 \%$ - в синей, 20\% - в зеленой, 50$73 \%$ - в красной области [18, с. $812-822$; 9, c. 109-110].

\section{Влияние УФ-излучения}

В литературе широко известно негативное действие ультрафиолетового излу- чения, однако доказано, что УФ свет низ-

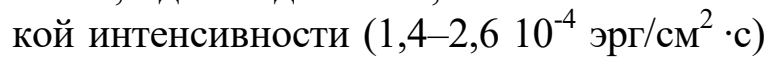
и короткой продолжительности (0,5-1 мин) способствует биосинтезу пигментов во многих растениях в первые одну-две недели их облучения. Установлено, что UVB излучение стимулирует формирование листьев и рост междоузлий, ускоряет формирование корней регенерантов картофеля на ранних этапах онтогенеза (1-3 сут) [32, с. 287-295]. Биосинтез пигментов не только не претерпевает нарушений, но идет более интенсивно у растений в первые одну-две недели их облучения.

Доказана эффективность ультрафиолетового облучения при яровизации посадочного материала при интенсивности, схожей с естественной солнечной. Растения, выросшие из клубней, облученных УФ, отличаются от контрольных большей высотой и более развитой листовой поверхностью [29, с. 337]. Природа наблюдаемых ростстимулирующих эффектов не исследована в достаточной степени. Они могут быть результатом как индукции специфических антистрессовых, так и каких-либо общефизиологических регуляторных систем.

\section{Влияние инфракрасного излучения}

Инфракрасное (ИК) излучение занимает в спектре область между красной частью видимого света (740 нм) и микроволновым радиоизлучением (2,5 мкм) [7, с. 12]. Электромагнитные волны данного диапазона передают энергию телам в виде тепла и излучаются нагретыми объектами. ИК свет не имеет субстратного значения в фотохимических реакциях, однако может оказывать важное регуляторное влияние, создавая благоприятную температуру для протекания биохимических реакций. Таким образом, инфракрасное освещение в условиях светокультуры может быть удобным инструментом для регуляции температуры листовых поверхностей, обеспечивая оптимальные условия для фотосинтеза и развития растений. 


\section{Заключение}

Таким образом, для увеличения продуктивности картофеля в условиях светокультуры необходимо учитывать сортспецифическую реакцию картофеля, осуществлять детальный подбор интенсивности освещения, продолжительности фотопериода и спектрального состава освещения. Импульсный и комбинированный режимы освещения являются перспективными объектами изучения при оптимизации условий культивирования картофеля как с точки зрения повышения продуктивности, так и экономии электроэнергии. Анализ имеющихся в литературе результатов исследований роста картофеля при искусственном освещении позволяет сделать вывод о целесообразности использования для освещения растений ламп белого света, достаточно интенсивных в области ФАР, с преобладанием в красной области спектра и негативном влиянии узкоспектрального освещения.

Ультрафиолетовое облучение низкой интенсивности при грамотно подобранном режиме может оказывать благоприятное воздействие на рост и развитие проростков картофеля, а инфракрасное излучение может быть удобным инструментом для поддержания комфортной для растений температуры. Однако результаты, полученные в данном направлении, имеют в настоящее время разрозненный и несистематизированный характер и требуют уточнения, многие эффекты являются не изученными, а предмет исследования в целом требует более углубленного изучения.

\section{Библиографический список}

1. Акулинкина Д.В. Ассоциация светоиндуцируемых стрессовых HliA/HliB белков с фотосистемами клеток цианобактерии Synechocystis PCC 6803: дис...канд. биол. наук: 03.01.04. - М., ИНБИ РАН, 2016. - $134 \mathrm{c}$

2. Ващченко Т.Г., Шакурова С.Х. Биотехнологические приемы оздоровления посадочного материала картофеля // Молодежный вектор развития аграрной науки. Материалы 63-й студ. конф. - Воронеж: ВГАУ, 2012. - С. 189-192.

3. Головацкая И.Ф. [и др.] Оптимизация условий освещения при культивировании микроклонов Solanum tuberosum L. сорта Луговской in vitro // Вестн. Томского гос. ун-та. Биология. - 2013. №4 (24). - C. 133-144.

4. Гранкова Л.И., Савина О.В. Выращивание пробирочных растений картофеля с использованием некогерентного красного света // Научно практические аспекты инновационных технологий возделывания и переработки картофеля. - ФГБОУ ВПО РГАТУ, 2015. - С. 62-66.

5. Дорофеев В.Ю., Медведева Ю.В., Карначук Р.А. Селективный свет и продуктивность растений картофеля в условиях in vitro и гидропонного культивирования // Актуальные проблемы картофелеводства: фундаментальные и прикладные аспекты. - Томск: ТГУ, 2018. - С. 215-218.

6. Заец B.H. [и др.] Молекулярные механизмы устранения растениями повреждений ДНК ультрафиолетом // Цитология и генетика. - 2006. - С. 44.

7. Кайгородов Р.В., Чудинова Л.А., Москвина Н.В. Спецглавы физических и химических наук: инструментальные методы исследований [Электронный ресурс]: учеб. пособие - Пермь, ПГНИУ, 2016. - 129 c.

8. Кондратьева М.Г. Обоснование энергосберегающего режима облучения растений // Вестник Ижевской государственной сельскохозяйственной академии. - 2014. - №. 4. - С. 41-46.

9. Коновалова И.О. Определение оптимальных параметров светодиодного освещения листовых овощных культур применительно к витаминной космической оранжерее: дис... канд. биол. наук: 14.03.08; 03.01.06. - Москва, ГНЦ РФ ИМБП РАН, 2016. - 177 с.

10. Кононенко А.Н. Влияние различных источников света на развитие мини-растений картофеля в условиях светокультуры // Известия Санкт-Петербургского государственного аграрного университета. - 2016. - №. 45. - С. 50-56.

11. Мартиросян Ю.Ц. [и др.] Фотосинтез и продуктивность растений картофеля в условиях различного спектрального облучения // Сельскохозяйственная биология. - 2013. - №. 1. - С. 107-112.

12. Мартиросян Ю.Ц. [и др.] Действие светодиодного облучения разного спектрального состава на фотосинтетический аппарат растений картофеля (Solanum tuberosum L.) в культуре in vitro // Сельскохозяйственная биология. - 2016. - № 5. - С. 680-687.

13. Медведев С.С. Физиология растений. - СПб.: БХВ-Петербург, 2012. - С. 36. 
14. Мякищева E.B., Соколова Г.Г. Влияние качества света на содержание фотосинтетических пигментов картофеля (Solanum tuberosum L.) в культуре in vitro // Известия АлтГУ. - 2014. - №3. C. $46-49$.

15. Никиткин B.A. [и др.] Роль селективного света в морфогенезе микроклонов Solanum tuberosum L. сорта Накра in vitro // Биотехнология, биоинформатика и геномика растений и микроорганизмов. Томск: НИ ТГУ, 2016. - С. 72-75.

16. Никонович Т.В., Шпак М.Ю., Левый А.В. Влияние спектрального состава света на морфофизиологические реакции растений-регенерантов Solanum tuberosum L. в условиях культуры in vitro //Редакционная коллегия. - 2014. - Т. 18. - С. 183-190.

17. Полевой В.В. Физиология растений. - М: Высш. шк., 1989.- 464 с.

18. Протасова Н.Н. Светокультура как способ выявления потенциальной продуктивности растений // Физиология растений. - 1987. - Т. 34. - №. 4. - С. 812-822.

19. Семененко B.E. Молекулярно-биологические аспекты эндогенной регуляции фотосинтеза // Физиология растений. - 1978. - Т. 25. - №. 5. - С. 902-921.

20. Синявская М.Г. [и др.] Экспрессия хлоропластного генома: современные представления и экспериментальные пути изучения // Вавиловский журнал генетики и селекции. - 2015. - Т. 19. №. 5. - С. 511-528.

21. Смашевский Н.Д. Экология фотосинтеза // Астраханский вестник экологического образования. 2014. -№2 (28). - С. 165-180.

22. Тарчевский И.А. Основы фотосинтеза. - Казань: Изд-во Казан, ун-та, 1971. - С. 130.

23. Тихомиров А.А., Шарупич В.П., Лисовский Г.М. Светокультура растений: биофизические и биотехнологические основы // Новосибирск.: Изд-во СО РАН. - 2000. - $213 \mathrm{c.}$

24. Федорова Ю.Н., Лебедева Н.В. Влияние света разного спектрального состава на рост растений картофеля in vitro // Известия Великолукской государственной сельскохозяйственной академии. 2016. - №4. - C. 2-7.

25. Фелалиев P.C., Наврузбекова М. Фотореактивация спектральных свойств растений при УФингибировании // Доклады Академии наук Республики Таджикистан. - 2007. - Т. 50. - №. 1. - С. 71-75.

26. Цыганкова B.A. [и др.] Генетический и эпигенетический контроль роста и развития растений. Гены фотоморфогенеза и регуляция их экспрессии светом // Биополимеры и клетка. -2004 . - Т. 20. - №. 6. C. $451-471$.

27. Чернавская Н.М., Чернавский Д.С. Периодические явления в фотосинтезе // Успехи физических наук. - 1960. - Т. 72. - №. 11. - С. 627-652.

28. Чиков В.И. [и др.] Фотосинтез, транспорт ассимилятов и продуктивность у растений картофеля, выращенных при разной освещенности // Сельскохозяйственная биология. - 2012. - №. 1. - С. $72-77$.

29. Шаин С.С. [и др.] Свет и развитие растений. - М.: Изд. сельскохозяйственной литературы, 1963. - 623 с.

30. Шестаков С.В. Молекулярная генетика фотосинтеза // Соросовский образовательный журнал. 1998. - №. 9. - С. 22-27.

31. Шибаева Т.Г., Марковская Е.Ф. Влияние круглосуточного освещения на состояние фотосинтетического аппарата и рост растений огурца Cucumis sativus L. на ранних этапах онтогенеза // Труды Карельского научного центра Российской академии наук. - 2012. - №. 2. - С. 162-166.

32. Янчевская Т.Г., Ковалева О.А. Стимулирование морфообразовательных процессов в меристемных растениях картофеля (Solanum tuberosum L.) под действием ультрафиолетового облучения Вдиапазона // Физиология растений и генетика. - 2015. - Т. 47. - № 4. - С. 287-295.

33. Chehab E.W. [et al.] Arabidopsis touch-induced morphogenesis is jasmonate mediated and protects against pests // Current Biology. - 2012. - T. 22. - №. 8. - C. 701-706.

34. Emerson R., Chalmers R., Cederstrand C. Some factors influencing the long-wave limit of photosynthesis // Proceedings of the National Academy of Sciences of the United States of America. 1957. - T. 43. - №. 1. - C. 133.

35. Ghavidel R.A. [et al.] Effects of plant growth regulators and photoperiod on in vitro microtuberization of potato (Solanum tuberosum L.) //African Journal of Biotechnology. - 2012. - T. 11. - №. 53. - C. 11585-11590.

36. Jao R.C., Fang $W$. Growth of potato plantlets in vitro is different when provided concurrent versus alternating blue and red light photoperiods // HortScience. - 2004. - T. 39. - №. 2. - C. 380-382.

37. Kitaya $Y$. [et al.] Effects of light intensity and lighting direction on the photoautotrophic growth and morphology of potato plantlets in vitro // Scientia Horticulturae. - 1995. - T. 62. - №. 1-2. - C. 15-24.

38. Omar G.F. Growth Responses of Potato Plantlets Cultured In Vitro under Different Colors Light-Emitting Diodes (LEDs) // HortScience Journal of Suez Canal University. - 2017. - №. 6. - C. 65-71.

39. Son K.H., Oh M.M. Leaf shape, growth, and antioxidant phenolic compounds of two lettuce cultivars grown under various combinations of blue and red light-emitting diodes // Hort.Science. - 2013. - T. 48. №. 8. - C. 988-995. 
40. Stutte G.W., Yorio N.C., Wheeler R.M. Interacting effects of photoperiod and photosynthetic photon flux on net carbon assimilation and starch accumulation in potato leaves // Journal of the American Society for HortScience. - 1996. - T. 121. - №. 2. - C. 264-268.

41. Subbotin E.P. [et al.] Влияние искусственного солнечного света на рост и развитие растенийрегенерантов Solanum tuberosum // Turczaninowia. - 2018. - Т. 21. - №. 2. - С. 32-39.

42. Tennessen D.J., Bula R.J., Sharkey T.D. Efficiency of photosynthesis in continuous and pulsed light emitting diode irradiation // Photosynthesis research. - 1995. - T. 44. - №. 3. - C. 261-269.

43. Wheeler R.M., Tibbitts T.W. Growth and tuberization of potato (Solanum tuberosum L.) under continuous light // Plant Physiology. - 1986. - T. 80. - №. 3. - C. 801-804.

\title{
THE GROWTH AND PRODUCTIVITY OF POTATO (SOLANUM TUBEROSUM L.) IN PHOTOCULTURE
}

\author{
A.M. Varushkina ${ }^{1}$, N.P. Lugovskaya ${ }^{1}$, A.Yu. Maksimov ${ }^{2}$ \\ ${ }^{1}$ Perm Federal Research Center UB RAS \\ ${ }^{2}$ Institute of Ecology and Genetics of Microorganisms UB RAS
}

Potato (Solanum tuberosum L.) is one of the most valuable agricultural plants, which explains high interest in its optimal cultivating conditions study. Potato productivity in the conditions of northern latitudes can be greatly enhanced due to the use of additional light sources. The review focuses on the problem of optimal parameters selection of supplementary lighting: the intensity of the luminous flux, length of photoperiod, pulse and continuous regimes of illumination and spectral structure.

The article observes the influence of light intensity and the length of photoperiod on the growth and development of potato plantlets. It also reveals the problem of selection of optimal conditions in connection with cultivar-specific reactions of plants. The question of usefulness of applying pulse and combined regimes of illumination in photoculture is discussed in terms of productivity enhancing and electricity saving. The study gives experimental data from different authors on the influence of various light spectrums on the growth and development of plants and the pigment synthesis. The choice of illumination with wide spectral characteristics and a certain ratio of separate spectrums intensity is justified. The possibility of applying short-time UV radiation for potato plantlets was revealed as a way to stimulate the growth and biosynthetic processes. Infrared radiation can be useful for thermoregulation of optimal conditions for photosynthesis and other physiological processes.

Keywords: potato plants, Solanum tuberosum L., photosynthesis, light-emitting diodes, LED, photoreceptors, light spectrum.

\section{Сведения об авторах}

Варушкина Александра Михайловна, младший научный сотрудник, Пермский федеральный исследовательский центр УрО РАН (ПФИЦ УрО РАН), 614900, г. Пермь, ул. Ленина, 13А; e-mail: saschavaruschkina@yandex.ru

Луговская Надежда Петровна, кандидат биологических наук, старший научный сотрудник, ПФИЦ УpO PAH; e-mail: nadido@yandex.ru

Максимов Александр Юрьевич, кандидат биологических наук, доцент, старший научный сотрудник, Институт экологии и генетики микроорганизмов УрО РАН - филиал ПФИЦ УрО РАН (ИЭГМ УрО РАН), 614081, г. Пермь, ул. Голева, 13; e-mail: almaks1@mail.ru 